\title{
Cecilia O'Reilly
}

coauthor of WYD Krakow 2016, The Largest European Event of the 21st Century, WYD 2016 International Media Team Coordinator, Content Director at CAST Catholic

\section{Tips for World Youth Day Panama 2019, passing on the experience of the past}

\section{Introduction}

Fresh graduates job hunting are well aware of the frustrations one faces: most employers, above and beyond anything else - your degrees, grades etc. - are looking for individuals with experience in that respective field. While analyzing and providing tips for those job searching is by no means the object of this article, an important point underlining the motive for writing it has been highlighted: experience is everything. Few people, if any, would deny that statement. Experience is invaluable on every level, from our personal to professional lives. Past experience offers individuals the know how, the dos and don'ts, to navigate a given situation, limit mistakes, exploit strengths and opportunities, and thus provide an overall higher likelihood of success. How often have you said, or heard someone say, with a note of exasperation, "if only I had experience!" Because, 
as no one would deny, we don't always have the luxury of it, even in the some of the most daunting situations.

World Youth Day (WYD) is one such situation that faces that hard reality. In its just over thirty year history, only two of its fourteen editions have been in the same location, Rome (1986 and 2000), which was the place of its birth. Every two to three years, a new host diocese and organizing committee must relearn what their predecessors did before them, must face an overwhelming task of organizing and communicating a massive international event with little to no experience under their belt. Not to mention, organizers must achieve this feat in a very short timeframe. This article is written with those individuals in mind, specifically Panama, the next WYD organizers. While reading these pages may not afford the opportunity to acquire experience, it will afford the opportunity to learn from experience, perhaps second best to having it. With that in mind, this article will focus on the author's area of expertise and, well, experience. That field is communications. So, the specific scope of this article is to serve WYD Panama communicators, but holds overarching principles that may serve Church communicators in general.

\section{Contents and structure}

Fundamentally, what is the value of experience? To be able to evaluate situations, processes, and reassess them so that we do better next time we are at the same crossroads. In other words, the contents of the article is not merely to document experience, but to offer tips for future organizers to implement based on it. Specifically, the article will cover a handful of large Church event overarching issues, and offer some tips for how to effectively address them. Here, the reader must permit two disclaimers: first, this article is by no stretch of the imagination comprehensive. The organization, and thus communications, of a WYD is extremely complex, comparable to an Olympics or World Cup. If this article were to be comprehensive, it would take up the entirety of this book and, perhaps, more. That is not the intent. Instead, this article is meant to offer some general guidelines to follow, and resources to find additional help and information. 
Second, this article is, in reality, a compilation of the International Media

Team's experiences and written research, which were based not only on subjective experience but also official reports and surveys. Two recently published works in particular will be quoted with frequency throughout this work, ${ }^{1}$ as well as various articles published by the team, all of which discuss all of the topics below in much more depth and detail.

\section{Tips for Panama}

\subsection{Define sommunications to do communications}

To do a job with any sort of success, we must know what it is first. Namely, we need to define the job at hand. In the words of Juan Manuel Mora, "In order to manage an activity well, it is first of all necessary to know what it is, to identify its component elements as well as its dynamic."2

So, what of communications at large Church events, specifically WYD? WYD Madrid's Executive Director emphasizes: 'everything is communications.' What precisely does that mean? Another way to say this is that 'everything communicates' the event to the various publics, and transmits the events message effectively or not. And, what the stakeholders receive and perceive about the event is precisely what communications concerns itself with: "communications is in charge of whatever is told to participants and other stakeholders (authorities, sponsors, neighbors, the general public, and the media) through the website, social media channels, press conferences and releases, etc." 3 To be clear, 'what is told' is meant

1 The two works were both published in 2018. The first is Megaevents of the Catholic Church: A Logbook for Organizers and Communicators, coord. Y. de la Cierva. The second work is a communications case study, P. Guzik, C. O'Reilly WYD 2016 Krakow: The Largest European Event of the 21st Century, Kraków 2018.

2 J. M. Mora, Strategic Management of Communication in the Church, in: Strategic Management of Church Communications: New Challenges, New Directions, eds. J. M. Mora, D. Contreras, M. Coraggio, Rome 2007, p. 36.

3 Y. de la Cierva, J. L. Black, C. O'Reilly, Managing communications for large Church events, "Church, Communication and Culture" 1 (2016) 1, pp. 110-134,

DOI: $10.1080 / 23753234.2016 .1181308$ (29.05.2018). 
90 in the broadest sense, not mere verbal communications. At WYD, for instance, "everything communicates: the city decorations, volunteers behavior, economic management, the beauty of the liturgy, etc."4 Each and every one of those examples are touching stones with one or more publics, and form their perception of the event, its message and mission. Various professionals in the communications field stress, thus, that communicators should feel the weight and responsibility of the entire event, as communications permeates all. ${ }^{5}$ In other words, the Communications Department has a unique character in the sense of its universality. Communications is not an independent task that can be self-contained within a department, precisely because its job is to effectively communicate the WYD message to all the publics, through every point of contact and activity, which occurs through every department of the Local Organizing Committee (LOC).

The experience at WYD Krakow 2016 was overall positive, but not without its road bumps, as is always the case. One thing that the LOC well understood was the immensity and importance of communications, assigning the greatest number of personnel to it. This allowed the Communications Department to establish a comprehensive operation. It was divided into 9 sections (Content, Social Media, Website, Press Office, Marketing and Promotion, Translations, Audiovisuals, Graphic Design, and IT) each with a coordinator that led that specific team, reporting to the Department Coordinator who in turn reported to the Communications Director. ${ }^{6}$ While 'communications is everything' may have been understood hypothetically, however, it was not executed in practice. Each LOC department functioned not only independently from each other, but also almost secretively, guarding their information and activities from one another. Needless to say, this did not translate well for communications. For instance, it meant the Media Office would discover news about the event simultaneously to the media, i.e. at press

4 P. Guzik, C. O'Reilly WYD 2016 Krakow: The Largest European Event of the 21st Century, op. cit., p. 74.

5 P. Guzik, C. O'Reilly WYD 2016 Krakow: The Largest European Event of the 21st Century, op. cit., p. 74.

6 This organizational structure was inspired by WYD Madrid 2011, the experience of which was documented in a case study World Youth Day Madrid 2011, a great resource for Krakow. 
conferences, and sometimes even after or through the media. Instead,

the Media Office should have been receiving this information in advance through official internal channels, so they could have the messaging prepped and applicable stories for the media when the information was formally released. That is just one example of many similar issues the Communications Department faced. This made it near impossible for the various sections to work strategically and effectively. Without knowing what was going on throughout the LOC, the Communications Department could not and cannot accurately communicate with the publics through the platforms that fall under their responsibility, or ensure the communications strategy is being implemented elsewhere the LOC is interacting with publics. The consequences? Fragmented communications and a loss of credibility with stakeholders.

In order to overcome these issues, the following recommendations are proposed:

a) Early on, appoint a communications coordinator assigned to each department in the LOC. Their responsibility is to establish a relationship with the department's director, attend meetings, keep the latter informed about communications activities, and report back to the communications personnel. Simply, they serve as an bridge between the communications department and the other departments to keep open communications, and help ensure the WYD communications strategy and message is being communicated through each department's work, activities, and interaction with the public.

b) The communications director must be privy to all information related to the event, and have a voice at decision-making meetings. It is their job to ensure each and every decision is staying true to the WYD's mission, and falls within the communications strategy, recalling that every detail is communicating the event. This is a mere reiteration of what past organizers have stressed:

The communications director should never see his role as passing on information from the organization to the public through the media or the website. Rather he has to make sure that the criteria for successful communication are present in all decision making. To do so, 
he has to be part of the organizing committee, participate in all meetings with the civil authorities and with the various offices of the Holy See. It is indispensable to have an active interest in everything, and to influence how the event is organized. ${ }^{7}$

c) Distinguish all your publics, external and internal, and make sure that each touchstone the LOC has with them is included in the communications strategy. Make sure that strategy is clearly defined, in writing, communicated, and in the official working language of the LOC (even if that is not the national language). While it is worth stressing the importance of the Communications plan and strategy, here is not the place to develop it. For resources, see footnote below. ${ }^{8}$

\subsection{What communications is not, divide and conquer}

As we just stated that "communications is everything" the title "what communications is not," does not naturally follow. Communications is everything, but everything insofar as it relates to content. Mora shares this point: "Strategic Management of communication obliges one never to lose the essential point of view. The main thing for the Church is to transmit its 'message of salvation.' Consequently, everything which bears on contents has a preferential place in the work of the department of communications." "As noted, contents in Church communications is concerned with the 'message of salvation', that is, Jesus Christ himself.

That means, logistical and technical aspects cannot bog down the communications department, and deter it from focusing on content. Because media operations, however, relates to the media, it is commonly mistook as a responsibility of the communications department. Nothing

7 Y. de la Cierva, J. L. Black, C. O’Reilly, Managing communications for large Church events, Church, Communication and Culture, op. cit.

8 The two recent published works, by members of the International Media Team, discuss the need, importance and contents of the Communications Plan. The works are, as listed above, Y. de la Cierva, Megaevents of the Catholic Church: A Logbook for Organizers and Communicators, op. cit.; P. Guzik, C. O'Reilly, WYD Krakow 2016: The Largest European Event in the 21st Century, op. cit.

9 J. M. Mora, Strategic Management of Communication in the Church, op. cit., p. 50. 
is further from the truth. Media operations is "in charge of the techni-

cal aspects of communications: the facilities and functions of the media center, the risers and pools at every event and how to reach them, the TV feed and the audiovisual services to be provide to radio and TV networks, and the media credentials." ${ }^{10}$ De la Cierva stresses, thus, that media operations is a different profession entirely, requiring a different skill set and area of expertise. In other words, when it comes to content and logistics, 'divide and conquer', or, better said, 'divide in order to conquer!' Media operations can and should be outsourced so that the communications department can focus on content. That content, for WYD, is the Catholic Church's message of salvation; a very important and yet sensitive, misunderstood message in a modern secularized world.

At WYD Krakow 2016, it was a unique situation with its pros and cons; again, as is always the case. The Archdiocese of Krakow decided to outsource media operations to the national Catholic News Agency, KAI, contingent to the Polish Bishops' Conference. KAI then partnered with the state owned agency, PAP, to manage all media operations together. In principle, this was a wise decision ${ }^{11}$ and could have worked out well. Due to the physical distance ${ }^{12}$ and autonomous work culture, there was no collaboration between the communications personnel and media operations. This mishap brings us to another important distinction: we must divide, not divorce content and logistics. Communications and media operations must have a collaborative relationship, even while falling under the responsibility of different departments or entities. One of the main problems that arose during WYD Krakow, was that there was no working relationship and fluid channels of communications between the communications department and KAI and PAP. The latter were further outsourced media relations, a content specific task, and

10 Y. de la Cierva, Megaevents of the Catholic Church: A Logbook for Organizers and Communicators, op. cit., p. 297.

11 Guzik lists three reasons for this being a strategic decision. See P. Guzik, C. O'Reilly, WYD 2016 Krakow: The Largest European Event of the 21st Century, op. cit., p. 158.

$12 \mathrm{KAI}$ and PAP were headquartered and ran operations in Warsaw, while the LOC worked in Krakow, the location of the WYD. 
94 forthwith ran the official online press room, popemobile2016.com. This site provided informative content, embargoed texts etc. for the journalists, a platform that thus helped to shape the narrative. While this can lead to a variety of complications ${ }^{13}$, ultimately this set more of a competitive tone between communications and media operations, rather than a collaborative one.

Tips to tackle this relationship:

a) Always outsource media operations to professionals in that field. ${ }^{14}$ Never leave media operations up to the communications department. Not out of fear they are incompetent, but because it will deter them from developing content, their actual job in fact.

b) Although the recommendation is to divide the two tasks, communications and media operations, don't divorce them from one another. Designate official and open channels of communications between the two, and establish expectations from the get go.

Media operation managers should know and accept in advance that all aspects that imply decisions on content should be consulted with the communications department. For instance, the process of credentialing is clearly one of the competencies of media operations; but the selection of pools with special access to some venues is linked to the media strategy... and is a communications decision. ${ }^{15}$

c) Never, no matter what the circumstances are, outsource content. ${ }^{16}$ The communications department has the very fine and delicate task of communicating WYD's message, Jesus Christ, to all the publics through the entirety of the event, through every interaction and point of contact.

13 See last tip for one, concerning Keeping Perspective.

14 See Y. de la Cierva, Megaevents of the Catholic Church: A Logbook for Organizers and Communicators, op. cit., Chapter on Media Operations, for reason why outsourcing is better than hiring in this particular situation.

15 Y. de la Cierva, Megaevents of the Catholic Church: A Logbook for Organizers and Communicators, op. cit., p. 299.

16 Y. de la Cierva, Megaevents of the Catholic Church: A Logbook for Organizers and Communicators, op. cit., p. 224. 
Outsourcing content runs the risk of losing perspective ${ }^{17}$, or losing site of WYD's message. ${ }^{18}$

\subsection{Remember "you are only human"}

Another way to phrase the title is, "ou are not a god". That is not an insult. No one is. What naturally follows is that "you cannot do it all." This is important to keep in mind for two reasons, crystallizing into two recommendations.

First, we all face the temptation to bite off more than we can chew, and particularly at large Church events. There are endless tasks that emerge daily, and we want to tackle them all, often head on. Partly because there are limited resources, so we don't know where to turn for help, partly because the average profile is an energetic and driven individual, inspired by the mission and ready to work tirelessly day and night typically due to their love for the Church. Further, they are working with a very fast approaching deadline: the event itself (a year away, months away, weeks away) which makes it all more tempting to push through unreasonable amounts of work. They start to miss meals, lose sleep, energy, patience, a clear thought process, and suddenly, become less capable to even take on their original workload, already a lot. And, in a blind will to push through, one often forgets to prioritize their actual job, which falls by the wayside. This affects all the people and processes that depend on them, and it only worsens as the event approaches, and during the event itself. So, though taking on more work may stem from an effort to serve more, it comes as a disservice to the organization, and the event itself. Remember "you are only human."

17 See tip Keeping Perspective, A Global Vision. This is an international event about the youth, and not a papal visit, which is easy to lose sight of.

18 Media relations was outsourced at WMOF Philadelphia as well as WYD Krakow 2016, but the problems which arose at the former were a different nature than the latter. Media relations was outsourced to a secular company that would have different priorities and values than the Catholic Church. This was problematic especially when sensitive incidents occurred that were prime opportunities for the Church to share Her message, but which the company wanted to hide from the media. 
Second, we all face the temptation to "predict" or plan for the ideal circumstances, or at least, not to face the reality of crisis, even mini ones at that. However, things often go wrong. In fact, it is not a matter of if things go wrong, but when and how things will go wrong. Sometimes, the things that go wrong demand our immediate and full attention, and our ordinary tasks must go by the wayside, either because we cannot bi-locate, or we don't have enough time in the day to do it all. That happens. As the event approaches, however, and during the event itself more so, it is of immense importance that our ordinary tasks always proceed and our authority is always present. Otherwise, whatever issue is at hand will only be magnified, or result in other issues. Naturally, the importance of this increases with one's level of leadership. That said, the higher level of authority you have the more important it is to remember "you are only human."

Keeping that fact in mind, our humanity, here are two invaluable tips:

a) New task, new person. This is simple in theory, challenging in practice, and essential in execution. When a new task crops up, don't eagerly take it on even if you are feeling extremely empowered to do so, especially in those lull times still leading up to the event. As the event approaches, the demands of your position will only increase and you need to be able to give your full attention to it. During the event itself, this is only intensified. If you have down time, use it to find someone to take on that responsibility. Or, if you don't have down time, then especially find someone to take on that responsibility so you can stay focused on your work. There are always many able and willing volunteers. Don't get caught up in work that can and should be delegated.

b) One job, two minds. If you are in any leadership position, appoint a second hand who you trust, and work closely with them so that they know your job as well as you. When things go wrong, as they inevitably do, sometimes it will impede you from being available to your work and your team which can have dire consequences. If you have someone who can speak in your name, and act in your absence, then you are well prepared for any reality, good or bad. 
Often, the Communications Department becomes so focused on communicating with external publics that communicating with internal publics and establishing official and effective channels of communications is quickly forgot. It seems almost too obvious to state, but too important to forgo: if there is deficient internal communications, then external communications will be fragmented and even, potentially, contradictory. The phrase coined by political lobbyist, Marcus Kurtz, seems all to applicable here, "as important as to inform is to be informed."19

The likelihood of fragmented communications increases with the scale of the event. So, granted, this has a very high probability at a mass international event, such as WYD, if there is lacking internal communications. Internal communications is not only a lost art within the Church, however, but a universal problem as Guzik points out:

It is a common perception among leaders, both in secular and religious institutions, that the communications department is only in charge of external communications. They neglect internal communications, or entrust it to another department as an accessory task to other issues related to personnel operations. ${ }^{20}$

The lack of integrated communications is not the only issue at stake here, however. It also prohibits people and teams from doing their job, or doing it effectively. In response to queries post WYD 2016, section coordinators stressed: "Internal communications was essential for their work and, if it could have worked better, their teams would have suffered less stress and frustration." ${ }^{21}$

19 M. Kurtz, The Impact of Personal Relationships in Organizational Communications, in: Church Communications: Faces, People, Stories, eds. A. Bailly-Bailliere, J. Milan, Rome 2014, p. 165.

20 P. Guzik, C. O'Reilly, WYD 2016 Krakow: The Largest European Event of the 21st Century, op. cit., p. 107.

21 P. Guzik, C. O'Reilly, WYD 2016 Krakow: The Largest European Event of the 21st Century, op. cit., p. 111. 
To give some examples of this within the WYD Krakow 2016 communications department: the International Media Team did not receive the list of credentialed media till immediately prior to the event, and only a partial list once received. Without knowing which foreign media were attending, and without access to their contact information, there was only so much they could do to facilitate WYD coverage. The Social Media Team, on the other hand, was not privy to official texts in a timely manner. Because of this, they had to process and communicate key messages live which is not only difficult, but much more prone to mistakes, especially considering that these individuals have been on their feet working around the clock for days.

In a nutshell, internal communications is a lost art in the communications field, but one with dire consequences for communications at large events. It must be a priority, and so much so that "the key to successful external communication is good internal communications, ensuring a coherent message," said Victoria Martin. ${ }^{22}$

To practice the much needed art of internal communications, here are some recommendations for WYD:

a) On one hand, establish official and clear channels of communication between sections in the communications department, and between departments in the organization: ${ }^{23}$ "an established and sharing system between departments is of fundamental importance." 24 On the other hand, limit the number of platforms being used for internal communications and choose the most universally known and user friendly ones. If there are too many platforms in the mix, and ones that are more difficult to navigate, then individuals will quickly abandon them and that can become just as ineffective as none at all.

b) Make sure that all decisions which are made that affect the communication department are put in writing and adequately communicated

22 Member of the European Parliament. This citation taken from Y. de la Cierva, Megaevents of the Catholic Church: A Logbook for Organizers and Communicators, op. cit.

23 In Krakow, though late in the day as a means to make up for no international communications, various whatsapp groups were formed for different teams, and between teams so everyone was on the same page.

24 Y. de la Cierva, Megaevents of the Catholic Church: A Logbook for Organizers and Communicators, op. cit., p. 235. 
to necessary members, via official channels and in the official language of

the LOC, even if that is not the same as the local language.

\subsection{Keep perspective, a global vision}

Stressing the need to have 'a global vision' at WYD has a twofold connotation. First, this event is not a papal visit. It is not about the pope, but about the youth, and the pope coming to meet them in their joy and sorrow, hopes and fears etc. Second, this event is not a national event, but an international one. Nevertheless, the unique cultural influence of the host country cannot be forgotten in the organization and communication. WYD is a celebration of youth, and their expression of Faith worldwide, but through the lens of a particular expression, the host country. To account for this unique dynamic, de la Cierva argues that it is neither local nor international, but 'glocal'. That is, both local and global, two ingredients that need to be mixed well for an effective communicative WYD recipe. ${ }^{25}$

Organizing committees that do not keep these two facts at the forefront of planning and organization, and communications, will get themselves into trouble. Imagine if organizers for an Olympics only prepped for their national teams, and communicators only strategized to reach national media and citizens. They would not only be overwhelmed when people from all four corners of the world descended upon them, they would simply collapse. And, fans from near and far and international media would return to their home to tell the story. Despite that reality, it is universally a temptation at WYD to become too focused on the pope and remain too inward to keep a 'glocal' perspective.

WYD Krakow 2016 did an excellent job of staffing the communications department with employees and volunteers from all over the world. This facilitated keeping an eye beyond its borders, but there was still so much that could have been done. For instance, most of the meetings and important discussions took place in Polish, even though the official language of the committee was English. This automatically negated interna-

25 Y. de la Cierva, Megaevents of the Catholic Church: A Logbook for Organizers and Communicators, op. cit., p. 214. 
100 tional advisors, employees and volunteers from partaking in discussions and having a say in decision making where appropriate and necessary. The consequence that naturally followed was that planning had less of an international character, as those behind them had more of a national mindset. In other words, there was an overdose of 'local' and underdose of 'global' in the recipe. Another example, more media focused, was systems in place for media operations. While KAI, the Catholic News Agency, had the benefit of experience on their side, their experience was with papal visits, and not with WYD. Two different beasts entirely. Instead of experience being a foundation for their work, it was a crutch in this case.

WYDs, on the contrary, are intrinsically international events with a third of reporters coming from abroad and many broadcasters willing to have stand up positions and satellite trucks. In this case, the experience of past events blocked their interest in learning... 5610 media representatives from 82 countries were accredited to WYD - 3, 794 from Poland and 1,816 from abroad. It was the largest number of journalists ever accredited to a religious event in Poland. ${ }^{26}$

In short, the importance of a glocal mindset permeates all communication with all publics. The following are a couple recommendations to maintain the right perspective:

Glocal Perspective:

a) Use the official language of the LOC at all meetings without exception. Put all decisions in writing and communicate them to necessary parties in that same language.

b) International media will most benefit from an international team on the grounds able to communicate with them in their language about logistics and content, helping them find relevant and exclusive stories that most relate to their respective countries. So, bring on an International Media Team. ${ }^{27}$ Equally important is bringing this team on early enough to be

26 P. Guzik, C. O'Reilly, WYD 2016 Krakow: The Largest European Event of the 21st Century, op. cit., p. 159.

27 The International Media Team is comprised of communications professionals from around the world. It was formed at WYD Madrid 2011 by the executive director, Yago 
effective, and make sure they have easy and direct contact with other de-

partments to obtain necessary information for media in a timely manner.

Protagonist Perspective:

c) Make sure that content on all platforms is youth centered, not pope centered. Remember that the Pope is coming to encounter the youth, that is where his interests and focus is, and so should the communications strategy. ${ }^{28}$

\section{Conclusion}

One final tip, if permitted, and which brings us full circle, regards experience. You may not have it, but many professionals in the field do. Don't just read what other have to say, but ask for help, advice, guidance, support, etc. on the grounds from communications professionals. Many have gone before you, organizing and communicating WYD, and are ready and willing to help. "Don't be shy, ask for help!" 29 expressly noted members of the International Media Team ${ }^{30}$. Bring on a team of seasoned communications professionals to help you navigate the storm, and effectively communicate the 'message of salvation' to Panama, and the to the world. A hostile and broken world that is rejecting Christ in its formed ignorance, and thirsting for Christ in its unformed conscience. WYD communicators are commissioned with the task of presenting Jesus Christ to the world as he is: the answer to their questions, desires, fears, hopes, brokennesses, dreams and future.

de la Cierva, who has led the team through thick and thin. The team was present at WYD Madrid 2011, WYD Rio 2013, WMOF Philadelphia 2015, WYD Krakow 2016.

28 For ideas, see the WYD 2016 Krakow Social Media platforms. The Social Media team did an excellent job of promoting the youth through their various campaigns and initiatives.

29 Y. de la Cierva, J. L. Black, C. O'Reilly, Managing communications for large Church events, Church, Communication and Culture, op. cit.

30 The International Media Team is comprised of communications professionals from around the world. It was formed at WYD Madrid 2011 by the executive director, Yago de la Cierva, who has led the team through thick and thin. 
Cecilia O'Reilly was an International Media Coordinator for World Youth Day Krakow, 2016 and World Meeting of Families Philadelphia 2015. She co-authored a communications case study World Youth Day Krakow 2016, The Largest European Event of the 21st Century and was a contributing author to Megaevents of the Catholic Church: A Logbook for Organizers and Communicators. Post obtaining a Bachelors in Philosophy at Christendom College and a Licentiate in Institutional Communications of the Catholic Church at the Pontifical University of the Holy Cross, Cecilia became the Content Director for Catholic CAST Media, a content creation studio that strives to share the faith in dynamic ways in the digital era.

\section{Bibliography}

Church Communications: Faces, People, Stories, eds. A. Bailly-Bailliere, J. Milan, Rome 2014.

Megaevents of the Catholic Church: A Logbook for Organizers and Communicators, coord. Y. de la Cierva et al., Mexico City, 2018.

Cierva Y. de la, Black J. L., O’Reilly C., Managing communications for large Church events, Church, "Communication and Culture" 1 (2016) 1, pp. 110-134, DOI: 10.1080/23753234.2016.1181308 (29.05.2018).

Guzik P., O'Reilly C., WYD 2016 Krakow: The Largest European Event of the 21st Century, Krakow 2018.

Strategic Management of Church Communications: New Challenges, New Directions, coords. J. M. Mora, D. Contreras, M. Corraggio, Rome 2007. 